\title{
Novas Aborgagens em Segurança do Trabalho
}

\section{Itiro Iida}

Engenheiro de Produção e doutor em engenharia pela USP, com curso de especialização no Japão. Analista de desenvolvimento científico do CNPq. Diretor administrativo da Abepro. Autor dos livros: Pequena e média empresa no Japão; e Ergonomia, projeto e produção.

CNPq/Assessoria de Planejamento

Av. W3 Norte 507 - Bloco B; C. Postal 6186 - 70740 - Brasília, DF

palavras-chave: Segurança do trabalho, ergonomia, acidentes do trabalho

Key words: Work conditions, ergonomics, work accidents

\section{RESUMO:}

Este artigo faz uma revisão crítica de alguns conceitos tradicionais em segurança do trabalho, entre os quais se incluem a teoria do "dominó" e a personalidade com prédisposição para acidentes. Mostra as mudanças de abordagens que comę̧aram a ocorrer a partir da década de 70, devidas principalmente ao melhor conhecimento sobre a natureza do erro humano, à mudança qualitativa ocorrida na natureza do trabalho humano e ao aumento potencial de prejuízos em acidentes graves, sem talar na maior conscientização da população mundial para esses problemas. O assunto já não é tratado apenas no nível subalterno das empresas, passando a fazer parte da política geral de atuação das mesmas, no nível estratégico, a longo prazo.

\begin{abstract}
:
This paper presents a critical review of some traditional work conditions concepts, emphasing the "domino" theory and the personality with accident predisposition. The paper also shows the changes on the work conditions studies approach that have beginned in the seventies, due mainly to the better knowledge about the character of human fails, to the increased losse caused by severe accidentes and to the great changes occured in the nature of the human work.

The subject - work conditions safety - raises nowadays to a theme treated at the strategic level of the companies, being present among the other subjects assigned to company administration responsability, and also present in companies long term politics formulation.
\end{abstract}

Rec. 07/90 Rev. 10/90 Apr. 10/90

PRODUÇÃO - Rio de Janeiro - Vol. 1 - № 2 - março 1991 - p.p. 63, 73 


\section{Os Mitos do Passado}

Até recentemente havia certos mitos na área de segurança do trabalho. Esses mitos geralmente colocavam a "culpa" do acidente no próprio acidentado e realizavam análises que se restringiam às máquinas e equipamentos diretamente envolvidos no sinistro e seu ambiente imediato. Desta forma, isentavam praticamente os responsáveis pela criação das situações perigosas de trabalho e que quase "condenavam" os trabalhadores ao acidente. A superficialidade das análises levava praticamente a situações de imobilismo, onde as máquinas, equipamentos e sistemas produtivos eram considerados como dados do problema e, portanto, imutáveis. Hoje, os acidentes são vistos mais como oportunidades para se introduzir aperfeiçoamentos, para se prevenir problemas futuros. Entre aqueles mitos mais frequentes, podemos destacar o da personalidade com predisposição para acidentes e a teoria do dominó.

\section{Personalidade com Predisposição para Acidentes}

Estudos realizados no passado demonstraram que havia um certo grupo de indivíduos que se envolvia mais frequentemente em acidentes. Em relação a um outro grupo, considerado mais seguro, os coeficientes de frequência de acidentes apresentados eram estatisticamente diferentes. Isto levou à formulação da teoria da personalidade com predisposição para acidentes. Segundo a mesma, certo tipo de pessoas tendia a atrair mais acidentes, como se fossem verdadeiros "ímãs" de acidentes.

Essa teoria nāo é mais aceita, modernamente, porque não se chegou a nenhuma comprovação prática da mesma. $\mathrm{O}$ envolvimento de uma determinada pessoa em um maior número de acidentes pode ocorrer, em um certo periodo, mas isso não quer dizer que se trate de um atributo permanente da pessoa, como a teoria faz supor. Trata-se mais de uma questão circunstancial e temporária, que pode depender, inclusive, de causas externas. Ou seja, o "clube dos acidentados" não tem sócios vitalícios: alguns estão entrando e outros saindo, num movimento contínuo. Algumas pessoas permanecem mais tempo que outras, nessa situação, dependendo de diversos fatores como treinamento, motivação, doenças, supervisão, manutenção das máquinas, organização do trabalho, problemas na vida familiar, e assim por diante. Assim que essas causas fossem removidas, as pessoas deixariam de pertencer ao "clube". Ou seja, em vez de se estigmatizar as pessoas acidentadas, elas podem ser objetivamente apoiadas para que não se acidentem mais.

\section{Teoria do "Dominó"}

Segundo a teoria do dominó, também chamada de teoria de Heinrick (1959), o acidente e a lesão seriam causados pela ocorrência de diversos eventos encadeados no tempo: (1) personalidade com predisposição para acidentes; (2) atos inseguros; (3) condiçōes inseguras; (4) acidente; e (5) lesão.

De acordo com essa teoria, um acidente não aconteceria, mas seria causado pela sequência de eventos acima enumerados. Assim, um trabalhador com características negativas de personalidade (valentia, agressividade, teimosia, irresponsabilidade, etc.), tenderia a cometer atos inseguros. Se estes encontrassem condições inseguras, resultariam em acidentes, provocando lesões no trabalhador. A prevenção de acidentes deveria ser realizada pela eliminação de uma das " pedras do dominó", para interromper a cadeia de transmissão de eventos causadores de lesões. Não 
sendo possivel modificar significativamente a personalidade, a atuação deveria concentrar-se na eliminação de atos inseguros, através de treinamento e criação de uma consciência de segurança no trabalhador. Outro meio seria a eliminação das condições inseguras, por exemplo, providenciando-se proteções para as partes perigosas de máquinas e equipamentos.

Essa teoria tem sido contestada porque admite, como premissa, a existência de uma personalidade com predisposição para adentes que, como já vimos, é discutível. Outro problema é que a maioria dos acidentes não poderia ser explicada pela simples sucessão linear e temporal de uma cadeia de eventos. Esses eventos teriam um tipo de interação mais complexa, não se sucedendo, uns atrás dos outros, mas interagindo entre si. Isto significa dizer que a eliminação de um deles para se interromper a cadeia, na prática, pode não ser tão trivial como prega essa teoria.

\section{O Erro Humano}

O comportamento humano nunca é constante e não segue rigidamente os padrões estabelecidos. Ele sempre apresenta alguma oscilação, que pode ser ou não considerada um erro. Quando esta oscilação natural do comportamento humano produz algum resultado fora dos limites esperados, ou quando a capacidade humana para acompanhar as mudanças ambientais forem insuficientes, resulta em erro.

Portanto, é difícil caracterizar um erro humano sem ter uma clara definição do comportamento ou do resultado esperado, pois o mesmo não existe no sentido absoluto, mas como desvios anormais, em relação a determinados padrões estabelecidos. Esta caracterização se torna ainda mais difícil nos sis- temas modernos, onde os erros decorrem do processo de percep̧̧ão e de tomada de decisões, que nem sempre dependem de comportamentos visíveis do operador, mas de processos que ocorrem no seu sistema nervoso central.

Para que um certo desempenho seja considerado insatisfatório ou errado, é necessário haver um julgamento humano. Esse julgamento pode ser feito pelo próprio operador ou por terceiros.

Em geral, os operadores têm uma consciência crítica razoável para julgar os próprios erros. Assim, quando os resultados de suas ações não decorrem de acordo com aquilo que era esperado, ele geralmente sabe que cometeu um erro.

No caso de julgamentos realizados por terceiros, geralmente recaem em pessoas especializadas, como supervisores, inspetores de qualidade ou peritos de agências de seguros. Geralmente essas pessoas não presenciaram o erro e os seus julgamentos são realizados após um certo tempo da ocorrência do mesmo. Neste caso, esse julgamento fica na dependência de reconstruções analíticas e de determinadas suposições, que podem estar corretas ou não.

O treinamento e a experiência nem sempre contribuem para reduzir a incidência de erros, mas aumentam a sensibilidade para identificá-los, aumentando as possibilidades para que os mesmos sejam corrigidos a tempo, antes que produzam efeitos indesejáveis. $\mathrm{O}$ matemático Hadamard já dizia em 1945: “Ao fazer cálculos matemáticos, cometo tantos erros quanto qualquer estudante neófito. A única diferença é que sei quando cometo erros e os corrijo a tempo, não deixando que eles influenciem no resultado final'. Ou seja, pode-se dizer que o treinamento e a experiência atuam como "filtros", ajudando a eliminar os erros. 
A frequência dos erros depende das características do trabalho e da possibilidade de visualizar os desvios e realizar as correções necessárias, o mais rápido possível. A visualização do erro depende da facilidade de comparação entre o desempenho real e aquele esperado, e esta característica operacional pode ser deliberadamente introduzida no projeto de sistemas.

Por exemplo, no controle da pressão em um processo industrial, se houver um manômetro que indique continuamente esta pressão (contendo uma faixa pintada, dentro da qual deve ser mantida o ponteiro do manômetro), os desvios poderão ser corrigidos imediatamente, assim que forem constatados. Isto já não ocorre em um outro caso de misturas de substâncias químicas em um processo contínuo, onde a composição resultante é determinada "a posteriori", mediante análise na saída do processo. Isto significa que há uma certa demora entre a ação de controle e o conhecimento do seu resultado, favorecendo a ocorrência e a propagação dos erros. Neste último caso, os erros poderiam ser diminuídos com a introdução de um painel de controle que indicasse imediatamente os resultados das ações de controle.

\section{Variabilidade Humana}

As diferenças individuais entre as pessoas são usualmente maiores do que se supõe. Essas diferenças não se restringem apenas ao aspecto físico das pessoas, mas também quanto as suas qualidades intelectuais e psicológicos, que se refletem na eficiência do trabalho e também na qualidade do mesmo.

Por exemplo: funcionários burocráticos que executavam um tipo de trabalho quantificável, foram subdivididos em 4 grupos de igual tamanho, de acordo com as suas produtividades individuais. $\mathrm{O}$ acompanhamento das produçōes desses quatro grupos mostrou que o grupo do quartil mais produtivo apresentava resultados de até $350 \%$ superiores, em relação ao grupo menos produtivo. Em termos individuais, as diferenças eram mais acentuadas: as pessoas mais produtivas chegavam a produzir até 6 vezes mais que aquelas menos produtivas, trbalhando em condições semelhantes (Richardson, 1970).

Essas diferenças individuais também estão presentes em atividades que exigem percepção e tomada de decisões. Paternotte (1978) fez 0 acompanhamento de 8 trabalhadores que trabalhavam em regime de turnos, controlando uma coluna de destilação, devendo manter o processo dentro de um valor especificado. Ele descobriu que alguns trabalhadores eram mais precisos que outros, ou seja, mantinham desvios menores, em relação ao valor especificado (ver Figura 1). $O$ operador mais preciso atuava mais frequentemente nos controles, enquanto os outros só o faziam quando os desvios atingiam valores maiores. As diferenças entre o operador mais preciso (operador A) e aquele menos preciso (operador F) chegavam a $400 \%$, na faixa de variação.

Essas diferenças individuais podem ser reduzidas mediante seleção e treinamento dos operadores e pela introdução de realimentações de informaçōes para tomada de decisões, mas não podem ser completamente eliminadas. Desta maneira, os sistemas devem ser projetados de tal forma que uma certa faixa de variação possa ser considerada normal. Naturalmente, quanto mais estreita for essa faixa ou as exigências de precisão, maiores serão as possibilidades de ocorrência de erros humanos.

\section{Confiabilidade Humana}

Confiabilidade humana é a probabilidade de uma tarefa ser desempenhada com sucesso pelo homem. Ela depende das interações 


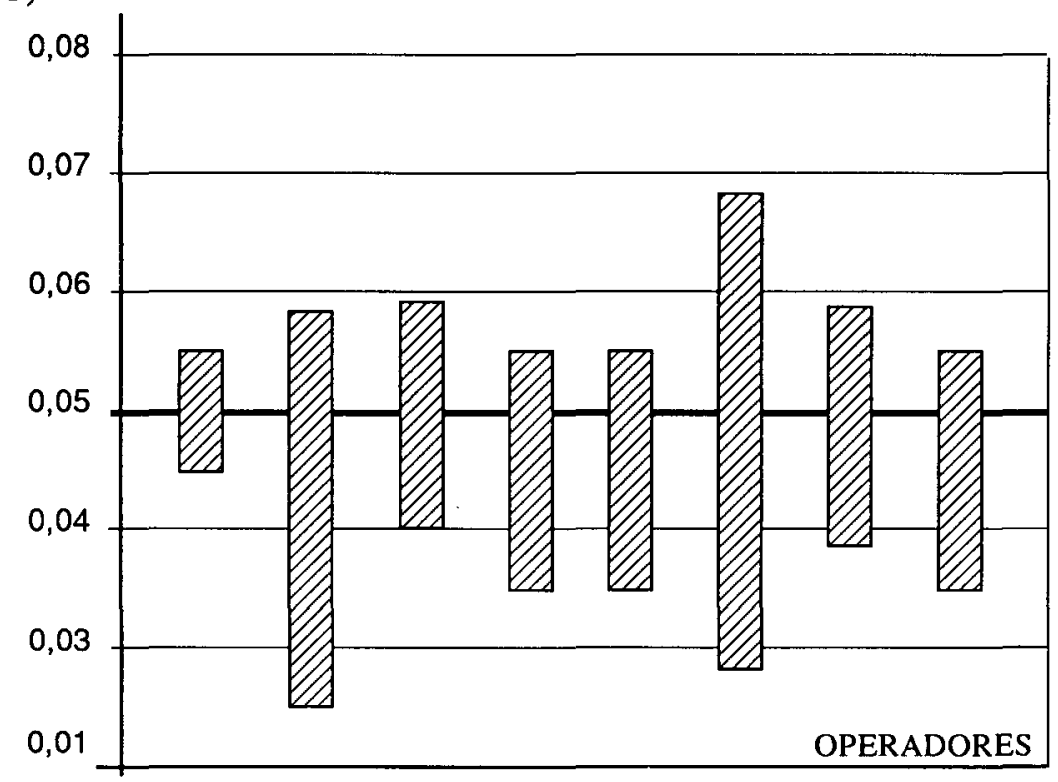

VALOR ESPECIFICADO DE CONTROLE

Figura 1 - Faixas de variações individuais apresentadas por oito operadores no controle de um processo em coluna de distilação (Patternotte, 1978).

do homem com o seu ambiente (máquinas, equipamentos e instalações) e da ocorrência de uma eventual falha em atender a determinadas expectativas. Este conceito baseiase, portanto, na existência de três elementos: um homem agindo; um ambiente que apresenta uma resposta considerada insatisfatória; e um critério de julgamento para considerála insatisfatória.

A existência de determinadas tarefas críticas, na indústria moderna, onde um simples erro pode produzir resultados verdadeiramente catastróficos, levou ao desenvolvimento de métodos probabilísticos para se estimar os riscos de acidentes para certos tipos de tarefas.

Na operação de centrais nucleares, por exemplo, existem tabelas de confiabilidade humana para cada tipo de tarefa. Por exemplo, a confiabilidade humana na leitura de um certo tipo de painel é de 0,982 . Isso significa dizer que, em cada 1000 leituras, pode-se esperar a ocorrência de 18 leituras er- radas. Naturalmente, esses cálculos probabilísticos se referem a uma média, para um certo número de operadores, pois, como já vimos, há grandes variações individuais de resultados, e o mesmo indivíduo pode apresentar resultados diferentes de acordo com a hora do dia e de um dia para outro.

O conhecimento da confiabilidade humana para diversos tipos de tarefas permite realizar projetos de sistemas com riscos calculados, para cada operação considerada crítica. Uma das formas usadas para se diminuir o risco é pela ligação de diversos subsistemas em paralelo. Assim, mesmo usando-se componentes individuais de confiabilidade relativamente baixa, poderão ser obtidos sistemas de maior confiabilidades. Por exemplo, ligando-se 4 componentes de confiabilidade 0,70 cada, em paralelo, a confiabilidade do conjunto será aumentada para 0,992 . Ou seja, com um só componente, o sistema apresentaria uma probabilidade de $30 \%$ de falha, e esta foi reduzida para apenas $0,8 \%$ no sistema com ligações em paralelo. 


\section{Evolução do Enfoque Sobre Acidentes}

Até recentemente, o trabalho humano na fábrica era caracterizado principalmente pela execução de operações manuais repetitivas, com pouco poder de decisão sobre as tarefas em execução. Com a introdução da automação nas estações de trabalho, o homem foi liberado dessas tarefas repetitivas, que passaram a ser executadas pelas máquinas programadas. Ao homem restou a tarefa de programar e monitorar as máquinas, para intervir em caso de alguma irregularidade. Essa mudança na natureza do trabalho humano exigiu uma adaptação dos métodos de análise de acidentes.

No sistema tradicional, os acidentes são analisados pela frequência de ocorrência e um relatório com descrição sumária dos mesmos. Esses relatórios normalmente apresentam poucas informações quanto às condições de trabalho no local do acidente e, portanto, não fornecem subsídios suficientes para um eventual aperfeiçoamento dessas condições.

Nos sistemas modernos, surgiu a necessidade de se identificar melhor as deficiências do projeto e do sistema de proteção, assim como, estimar o nível de risco envolvido nas operações. Surgiram, assim, os instrumentos de análise funcional, que fornecem muito mais informações para compreender os mecanismos causadores de acidentes. A partir dessas análises, podem ser elaboradas as propostas para o aperfeiçoamento do sistema. Estas se referem principalmente à imediata identificação de qualquer tipo de anormalidade, para que esta possa ser corrigida, ou até interrompida, antes que resultem em acidentes.

\section{Diagrama de Acidentes}

$\mathrm{Na}$ maioria dos casos, os acidentes não ocorrem gratuita e nem isoladamente. São quase sempre resultados da conjugação de outras falhas menores. A análise das interações entre os fatores causadores de acidentes levou, na última década, ao desenvolvimento da abordagem funcional. Ela se baseia na análise detalhada de acidentes reais, para se identificar os riscos e as falhas existentes, assim como as interações entre as mesmas, para se introduzir medidas preventivas no futuro. É como desenvolver sensibilidade para a percepção de determinacius "avisos" de que um acidente está iminente e, entāo tomar providências antes que ele ocorra, efetivamente.

Um exemplo desse tipo de modelo é o diagrama de acidentes (Leplat e Rasmussen, 1984), que tem o objetivo de identificar os aspectos que poderiam ser aperfeiçoados no futuro, em vez de se concentrar nas causas de eventos passados ou em apontar os "culpados", o que nada resolve.

Para se construir um diagrama de acidentes é necessário analisar as atividades envolvidas, para se detectar as variações que elas sofreram, em relação às suas condições normais, e cuja conjugação teria resultado no acidente. A Figura 2 apresenta um exemplo de análise de uma colisão de empilhadeira, que era usada para transportar cargas dentro de uma fábrica. No dia do acidente, a empilhadeira normalmente usada estava quebrada e, então, o operador foi obrigado a usar o equipamento de reserva. $O$ operador não estava acostumado a usar essa empilhadeira de reserva. Além disso, ela apresentava um defeito no freio e também tinha uma capacidade de carga menor que a empilhadeira 


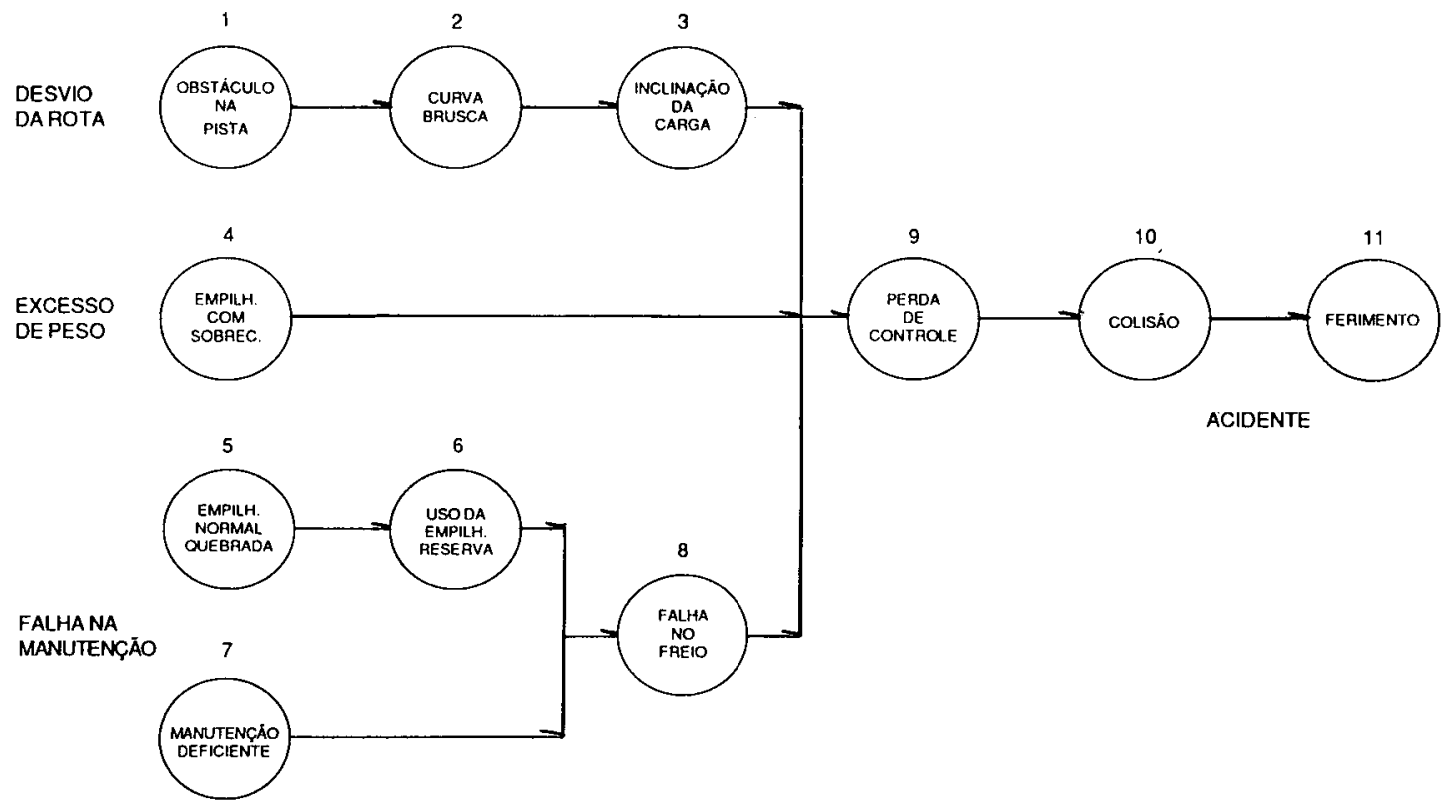

Figura 2 - Diagrama do acidente com uma empilhadeira (Leplat, Rasmussen, 1984). 
normal e, em consequência, ficou sobrecarregada. Durante o percurso, apareceu um obstáculo na pista, obrigando o operador a fazer uma manobra brusca, que provocou uma inclinação da carga. Somando-se a isso o excesso de peso e a falha no freio, resultou na perda de controle e uma colisão contra uma parede, causando um sério ferimento no operador, além dos danos materiais. No caso, pode-se dizer que a causa imediata do acidente foi o obstáculo na pista, mas antes já haviam ocorrido diversos antecedentes que poderiam funcionar como um "aviso" para possíveis acidentes. Removendo-se alguns deles ou evitando-se que eles ocorram simultaneamente, no futuro, é possível que acidentes do mesmo tipo possam ser evitados. Portanto, os diagramas desse tipo permitem identificar as anormalidades ou condições críticas que levaram ao acidente, sendo úteis para a formulação de medidas preventivas em casos semelhantes.

\section{Responsabilidades da Alta Administração}

$O$ índice de acidentes em geral não pode ser reduzido significativamente, enquanto a atuação de controle e prevenção se restringir somente ao operador e ao seu ambiente imediato, sem que isso faça parte de uma política mais global, decidida pela alta administração da empresa.

A existência de determinadas condições perigosas indicam que estas foram antecedidas de decisões que levaram à sua criação e implantação. Portanto, pode-se falar também na existência de decisões perigosas, que levaram à escolha de determinados tipos de equipamentos inconvenientes, à criação de condições hostis aos trabalhadores ou ao treinamento insuficiente dos operadores.
Muitas fábricas modernas, principalmente aquelas que apresentam grandes potenciais de perdas com acidentes, estão incluindo a segurança como assunto a ser tratado pela alta administração, no mesmo nível de outros assuntos estratégicos como finanças, marketing e produção.

A empresa Du-Pont, por exemplo, é apontada como sendo uma das pioneiras em incluir a segurança no planejamento estratégico (Griffiths, 1985). Para isso, ela baseia a sua política de segurança nos seguintes princípios:

(1) Todos os acidentes são evitáveis. Em princípio, todos os acidentes são considerados evitáveis, desde que se tomem as medidas preventivas necessárias. Esta atitude estimula o trabalho na prevenção, em oposição aquela negativista ou fatalista, que leva ao imobilismo e conformismo.

(2) A segurança tem importância estratégica. Os assuntos de segurança devem ser incluídos no planejamento estratégico da empresa, no mesmo nível da produção, finanças e marketing.

(3) A segurança é de responsabilidade da alta administração. A alta administração da empresa deve assumir a responsabilidade e a liderança na área, estabelecendo uma política de segurança para a empresa, as principais metas anuais a serem alcançadas e garantindo os recursos necessários à execução das mesmas.

(4) Todos devem trabalhar com segurança. O "espírito" de segurança deve permear por todos os escalões administrativos, atingindo todos os empregados da empresa, com a mesma ênfase que se costuma dar à produtividade e qualidade. Em cada setor, o respectivo chefe passa a ser o responsável pela segurança dos seus subordinados, devendo zelar pela segurança dos mesmos, nas atividades do dia-a-dia. 


\section{Programas de Segurança}

Baseando-se nos princípios acima apresentados, podem-se desenvolver programas de segurança. Esses programas procuram manter um conjunto de atividades hierarquizadas e coerentes entre si, para que os resultados previstos sejam efetivamente alcançados. São constituídos, em geral, das seguintes etapas:

(1) Definição da política de segurança. A política de segurança da empresa deve ser claramente definida, de modo que permita a elaboração de planos, com o envolvimento de diferentes níveis administrativos.

(2) Planos de segurança. Os planos devem ser formulados anualmente, em consonância com a política de segurança. Devem conter objetivos específicos a serem alcançados, com os respectivos cronogramas e previsão de recursos necessários. Esses planos devem conter algumas metas globais, em termos de redução da quantidade de acidentes ou do número de dias perdidos por acidentes.

(3) Envolvimento do pessoal. Através de treinamentos, palestras, demonstrações, simulações e discussões frequentes com os trabalhadores, alertá-los para as práticas seguras no trabalho e no sentido de notificar em qualquer tipo de irregularidade, solicitandose a imediata correção da mesma, antes que tome proporções maiores.

(4) Inspeções. As instalações da empresa devem ser inspecionadas frequentemente, tanto pelos responsáveis de linha (diretores, supervisores, chefes de departamento), como pelos especialistas em segurança. Os principais dirigentes devem fazer as inspeções periódicas, acompanhados dos respectivos chefes das áreas inspecionadas. Nessas inspeções, diárias ou semanais, devem ser verificados o estado das máquinas, a lim- peza e conservação, uso de práticas seguras no trabalho e assim por diante.

(5) Relatórios de acidentes. Devem ser elaborados relatórios escritos de todos os tipos de incidentes ou acidentes que causem perda material ou lesão. Mesmo aqueles incidentes de pouca importância, quando analisados em conjunto com outros, podem indicar certas tendências, demonstrando que algo não está indo bem e que é preciso tomar algum tipo de providência, antes que produzam prejuizos maiores.

A Figura 3 apresenta um exemplo de resultado obtido com a introdução de um programa de segurança (Griffiths, 1985). Ela apresenta os números de acidentes e os dias de trabalho perdidos em acidentes, durante 12 anos, em uma empresa do ramo químico, nos EUA. O programa de segurança foi introduzido nessa empresa em 1976. Antes da introdução desse programa, costumavam ocorrer cerca de 110 acidentes anuais com perda de tempo, totalizando cerca de 3000 dias perdidos ao ano. Com a introdução do programa, esses índices foram reduzidos significativamente, ano após ano. Em 1982, seis anos após a introdução do programa, o número de acidentes registrado foi de apenas 2 casos, com uma perda total de 21 dias.

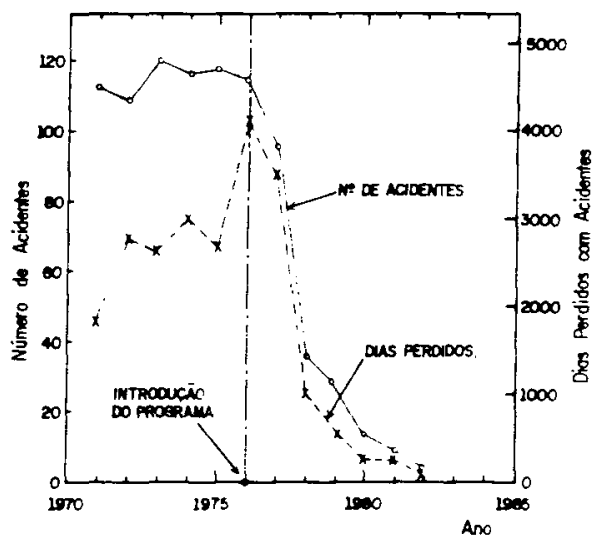

Figura 3 - Número de acidentes e dias perdidos com acidentes, antes e depois da introdução do programa de segurança. 
Estas cifras representam, respectivamente, 1,8 e $0,7 \%$ em relação às marcas anteriores à introdução do programa.

Em algumas empresas, esse tipo de programa é chamado também de "acidente zero", pois o objetivo do mesmo é o de erradicar totalmente os acidentes ou mantê-los tão próximos quanto possível do nível zero.

\section{Conclusão}

A partir da década de 70 , começou a haver uma mudança de abordagens em segurança do trabalho. Isto resultou da evolução da própria natureza do trabalho humano, com a introdução da automação e a consequente substituição dos processos musculares pelos processos mentais. Os sistemas operacionais também se tornaram mais complexos e integrados. Por outro lado, houve também uma conscientização maior dos trabalhadores e da população em geral.

Todos estes fatores contribuiram para uma mudança de postura gerencial em rulação aos acidentes. Elas passaram a ser consideradas de forma mais integrada, desde a concepção e projeto de novos sistemas, com especial ênfase no aspecto preventivo. Em consequência, elas ganharam um status maior dentro das empresas, passando a ser tratado como um assunto estratégico, a nível da administração superior dessas empresas.

\section{Referências Bibliográficas}

(1) GRIFFITHS, D.K., Safety Attitudes of Management, Ergonomics, 28(1),61-67, 1985.

(2) LEPLAT, J. e RASMUSSEN, J., Analysis of Human Erros in Industrial Incidents and Accidents for Improvements of Work Safety. Accid. Anal. and Prev. 16(2), 77-88, 1984.

(3) PATERNOTTE, P.H., The Control Performance of Operators Controlling a Continuous Distillation Process, Ergonomics, 21(9), 671-679, 1978.

(4) RASMUSSEN, J., Trends in Human Reliability Analysis, Ergonomics, 28(8), 1185$1195,1985$.

(5) RICHARDSON, M.W., Avaliação do Mérito, in MAYNARD, H.B., Manual de Engenharia de Produção, Vol. 6, Edit. Edgard Blücher Ltda., São Paulo, 1970. 